\title{
PRÁTICA PROFISSIONAL DOCENTE E SENTIDOS E SIGNIFICADOS SOBRE EDUCAÇÃO E FORMAÇÃO ${ }^{1}$
}

\section{Resumo}

Este artigo apresenta resultado de pesquisa que buscou desvelar quais sentidos e significados de educação e formação conduzem a prática profissional do docente do ensino superior privado, tendo por base o referencial teórico da Psicologia Histórico-Cultural em sua interlocução com o campo educacional. Trata-se de investigação de abordagem qualitativa, que adotou como procedimento de pesquisa o Grupo Focal desenvolvido com docentes de instituições de ensino superior privadas. Utilizou-se no tratamento dos dados, o procedimento de análise denominado Núcleos de Significação (AGUIAR; OZELLA, 2006) o que possibilitou uma aproximação dos sentidos e significados refletidos nas falas desses professores. Como resultado identificou-se que os sentidos e significados de educação e formação estão postos mais na base de suas profissões anteriores à docência, do que em aportes desenvolvidos por meio de formação inicial ou continuada, processos praticamente ausentes em instituições de ensino superior.

Palavras-chave: Formação de Professores; Pedagogia Universitária; Ensino Superior; Concepção de Educação; Sentidos e Significados

\section{INTRODUÇÃO}

\footnotetext{
${ }^{1}$ Apoio CAPES-Reuni - Coordenação de Aperfeiçoamento de Pessoal do Ensino Superior.

${ }^{2}$ Mestre em Educação (Programa de Pós-Graduação em Educação e Saúde na Infância e na Adolescência da UNIFESP); Endereço: Rua Lino Coutinho, 613, ap.24 - Ipiranga, São Paulo, Brasil. E-mail: robinsonjacintho@gmail.com.

${ }^{3}$ Pedagoga, Mestre e Doutora em Educação: Psicologia da Educação; Professor Adjunto III da Universidade Federal de São Paulo UNIFESP- campus Guarulhos, EFLCH, Departamento de Educação, PPGE em Educação e Saúde na Infância e na Adolescência e PPGE em Educação. Endereço: Estrada do Caminho Velho, 333 Pimentas. E-mail: magali.silvestre@unifesp.br
} 
SOUZA, R. J.; SILVESTRE, M. A.

Vislumbramos uma prática profissional docente, no ensino superior, que busque responder ao imperativo de uma educação conscientizada em meio a uma sociedade fortemente regulada pelo mercado. Disso, empenhamo-nos na conscientização de uma concepção de educação e de formação, que por intermédio de sua ação transformadora, ocupe uma posição relevante e decisiva na sociedade. Assim sendo, a seriedade assumida por essa ação profissional estabelece uma ponderação sobre a sua objetivação histórica e a conscientização de uma profissão.

Pensar na possibilidade de uma profissão que pode ser canal de transformação, também implica ser transformado pelo alvo da sua ação, a educação. Tal motivo é guiado não por preparação, mas, sim, pelo dever de uma contínua formação, uma vez que é por meio de sua práxis diária que o profissional desempenha-se como ser histórico. Do mesmo modo, a tomada de consciência docente para a humanização eu-outro é resultado de sua comparação com o mundo objetivo, decorrente da integração dialética da subjetividade do seu profissional com a objetividade de sua profissão.

Com isso, essa interação dialética se converte em intenção para uma adequada apreensão dos conhecimentos necessários para a profissão docente no ensino superior, assim como para sua ação educacional. Isso provoca dinamismo na conscientização profissional, da realidade e da unidade teoria e prática.

O que identificamos como "consciência docente" é a reflexão dialética do profissional sobre si e sua relação com seu contexto. Desse modo, esse processo não deve se limitar somente ao conhecimento da realidade, mas resulta na busca por sua transformação, reconhecendo suas influências e contradições. Por outro lado, sabemos que tal processo presume um posicionamento profissional-pedagógico por parte do docente - que se dá, substancialmente, pela formação -, opção esta que pode desenvolver, ou não, tal transformação.

Em nosso entendimento, o docente do ensino superior privado no Brasil não pode desconsiderar a força fundadora e recriadora dessa consciência, porque é possível ultrapassar a regulação que procura a todo tempo mascarar a realidade e sua atuação profissional pedagógica, pelo modelo de uma racionalidade técnica, impedindo-o de elaborar questionamentos sobre o sentido da educação, corroborando para a negação da importância pedagógica e didática do ato de ensinar no ensino superior, promovendo, desta forma, a perda das possibilidades de mudança no futuro. 
PRÁTICA PROFISSIONAL DOCENTE E SENTIDOS E SIGNIFICADOS SOBRE EDUCAÇÃO E FORMAÇÃO

Nessa direção, apresentamos nesse texto uma problemática que julgamos importante e que serviu de base para o desenvolvimento de uma pesquisa de mestrado que teve como questão norteadora desvelar quais os sentidos e significados de educação e formação conduzem a prática profissional do docente do ensino superior privado. O objetivo geral perseguido foi o de apreender as manifestações expressas por docentes de instituições de ensino superior privadas, de cursos de graduação, da área de Ciências Sociais Aplicadas, em relação à sua prática profissional. Buscamos uma reflexão sobre os docentes como seres sócio-históricos concretos e suas determinações, além de, a partir do conceito de consciência em Vygotsky e de uma concepção de educação emancipadora, a compreensão das formas de pensar, sentir e agir desses docentes e, por fim, a identificação de possíveis manifestações de tomada de consciência para determinação e emancipação em seu fazer docente.

A primeira parte do artigo oferece dados relativos aos docentes universitários para a geração de informações que subsidiaram a formulação da problematização, bem como sua análise para os objetivos da investigação. Apresenta, também, o estudo, ainda que sumariamente, sobre a formação do docente do ensino superior privado, no que se refere às aprendizagens desses profissionais, seus conhecimentos e especificidades da docência, o pedagógico, a didática e uma concepção de educação em sua ação intencional emancipadora.

$\mathrm{Na}$ sequência, apresentamos alguns componentes do aporte teórico-metodológico central da pesquisa que está baseado na Psicologia Histórico-Cultural especificamente em sua interlocução com o campo educacional.

Finalmente, apresentamos, parcialmente, os resultados do estudo alcançados ao explicitar alguns sentidos e significados que são atribuídos, por esses sujeitos, ao seu trabalho docente.

\section{ALGUNS DADOS SOBRE PROFISSIONAIS DOCENTES UNIVERSITÁRIOS}

Para compreendermos a docência universitária do ensino superior privado, como objeto de estudo, buscamos, primeiramente, obter alguns componentes que nos apresentassem um quadro real e isso foi possível por meio de dados disponíveis que demostram parte da constituição dessa realidade envolvendo os docentes de instituições de ensino superior (IES) privadas. 
SOUZA, R. J.; SILVESTRE, M. A.

O Censo da Educação Superior, em seu resumo técnico 2010, disponibilizado em $2011^{4}$, indica que houve nas IES um crescimento significativo entre o período de 2001 a 2010, no que se alude ao número de cursos oferecidos e a distribuição das áreas gerais de conhecimento dos cursos, conforme a participação de matrículas, que nos aponta para uma demanda necessária de professores para supri-las. Além disso, revelam a categoria administrativa das instituições que ofertam o ensino superior, demarcando que em 10 anos, ainda prevalece um percentual elevado de instituições privadas: “Em 2010, esses totais representavam: 88,3\% de instituições privadas, $4,5 \%$ estaduais, $4,2 \%$ federais e 3,0\% municipais (INEP, 2010a).

No que se refere à demanda de professores para atender o elevado número de IES no país, em sua sinopse estatística do ensino superior, o INEP indicou - por organização acadêmica e grau de formação, segundo a unidade da federação e a categoria administrativa que, no Brasil, existem 345.335 professores em suas funções docentes, afastados ou em exercício. Destes, 130.789 estão lotados em instituições públicas ${ }^{5}$, enquanto que nas IES privadas esse número é de 214.546 docentes (INEP, 2010b).

Ao analisarmos o resumo técnico do Censo da Educação 2011, verificamos que o número de docentes das IES privadas passou de 214.546 para 217.834. Ainda, no mesmo documento, constatamos que, no período 2002 a 2011, as instituições privadas mantiveram o regime de trabalho horista como política administrativa. Nas Universidades, Centros Universitários e Faculdades privadas, 54.489 docentes foram contratados em regime de tempo integral, 67.877 parcial e, a marca considerável de 95.468 docentes, em regime de trabalho horista (INEP, 2011).

Embora o INEP indique que houve uma redução no regime de contratação de trabalho horista, diminuindo de 55,8\%, em 2002, para 48,0\%, em 2010, em nosso ponto de vista, esse número é, ainda, bastante elevado e nos remete a avaliar as condições de trabalho desses profissionais, assim como o pouco tempo reservado para a formação desses docentes nas IES privadas. E, finalmente, quando recorremos aos dados referentes à titulação desses docentes, embora tenha elevado o número de professores com titulação máxima nas IES privadas, o número de doutores que atuam nessas instituições ainda é muito baixo, 15,4\% (INEP, 2010c).

\footnotetext{
${ }^{4} \mathrm{Na}$ época em que a pesquisa foi desenvolvida este era o documento mais atualizado. Foi mantido, nesse artigo, por tratar-se uma série histórica com dados consideráveis de um intervalo de dez anos. O Relatório do Censo mais atualizado, disponível, data de 2013.
}

${ }^{5} 78.608$ Federal, 45.069 Estadual e 7.112 Municipal. 
PRÁTICA PROFISSIONAL DOCENTE E SENTIDOS E SIGNIFICADOS SOBRE EDUCAÇÃO E FORMAÇÃO

Ao delimitarmos esse conjunto de dados às instituições privadas, encontramos inúmeras e diversas questões possíveis de serem problematizadas. No caso de nossa pesquisa, tais dados serviram de base para justificarmos a relevância de nosso estudo sobre a docência universitária, ao desejarmos compreender os efeitos dessa expansão de demanda e sua relação com a ausência de formação adequada aos professores do setor privado.

\section{O PEDAGÓGICO E O DIDÁTICO PARA A FORMAÇÃO DOCENTE}

A partir da consistência desses dados anteriormente apresentados, compreendemos que a expansão do ensino superior e o aumento dos docentes nesse setor, provocaram uma busca no campo de formação de professores sobre a docência universitária. Ao falar sobre a formação desse docente, no Brasil, em sua unidade de ação, é necessária, a partir da exigência da legislação vigente, a observação de processos formativos dedicados e específicos para atender essa demanda, como já é o caso dos cursos de licenciatura que oferecem formação para os professores da educação básica.

Esse profissional está situado em um contexto histórico, social e cultural definido, bem como a instituição de sua prestação de serviço educacional. Mas em meio à complexidade do ensinar faz-se imperativo ir além nos procedimentos de organização, concepção e processos formativos, que ultrapassam a simples tentativa de capacitar o docente tecnicamente para esse ofício.

Para Veiga (2010) existem alguns pontos que justificam cada vez mais o debate do tema acerca da formação desses docentes. Na síntese que extraímos de alguns pontos que a autora nos apresenta, temos: a problemática em torno do artigo 69 da lei 9.394/96, que limita a preparação desse profissional aos programas de mestrado e doutorado, denotando a ausência de uma formação pedagógica anterior para o exercício docente; as próprias políticas que regem a docência superior no que diz respeito à diferenciação institucional, onde algumas IES são categorizadas como "de pesquisa", enquanto outras são "de ensino"; as tensões e contradições envolvendo a pedagogia universitária iniciadas pelas políticas avaliativas; o processo de democratização do acesso ao ensino superior e a consequente heterogeneidade dos discentes; em decorrência desse ponto, o surgimento desordenado de IES e suas anomalias; o exercício de atividades diárias para o qual esse docente não recebeu nenhuma formação específica; e a contínua exigência no conhecimento científico desse docente no lugar do pedagógico. 
SOUZA, R. J.; SILVESTRE, M. A.

Nessa direção, para Pimenta e Anastasiou (2002) nos deparamos com uma problemática envolvendo esse nível de educação, que é da construção da identidade desse docente, pois, em seu espaço institucional de trabalho, o que se tem visto são, cada vez mais, profissionais de diversas áreas "que, em sua maioria, não tiveram formação inicial ou continuada para o exercício da profissão" (p. 24-25).

Isso nos leva a pensar acerca da necessidade do debate sobre a docência universitária, a partir da estrutura organizativa em que esses docentes trabalham, as competências e formação desses profissionais, pois, conforme Masetto (2003) destaca, em nosso país, tanto no passado como ainda hoje, sempre se privilegiou o domínio de conhecimentos e experiências profissionais como únicos requisitos para a docência nos cursos superiores. Isso tem uma explicação que vem de duas atitudes, que foi "tanto o modelo de ensino superior implantado no Brasil (o modelo francês-napoleônico - cursos profissionalizantes) quanto à crença de 'quem sabe, sabe ensinar'” (MASETTO, 2003, p. 11).

Aliado a isso, esse mesmo autor, questionando sobre quem é este docente, confirma que sua origem está ligada diretamente com as faculdades desenvolvidas no Brasil, onde os cursos superiores, com seus currículos seriados, focavam sua atenção exclusivamente para a formação de profissionais técnicos. Com a crescente demanda, tais instituições precisaram de alternativas viáveis para ampliação do corpo docente existente, conseguindo isso com a contratação de profissionais renomados que, no sucesso de suas carreiras profissionais, poderiam inspirar os alunos a se constituírem tão bons profissionais como estes que estavam aceitando o convite para lecionar.

No entanto, compreendemos que formação é condição sine qua non para a existência de um indivíduo em sua ação profissional. Assim, a formação em seus significados denota, entre outras coisas, a obtenção de saberes próprios que caracterizam esse indivíduo em sua ação, o que envolve elementos que são os modos de fazer e ser frente ao exercício profissional docente.

Desses modos de fazer e ser, destacamos que, a postura reflexiva sobre a prática docente é um elemento dentro do constructo formativo, que expõe os saberes e competências necessários à docência. Mas essa postura só terá êxito se antes tiver sendo sustentada por dois elementos da função específica da investigação do fenômeno de formação humana, que é a conceituação pedagógica e didática para aprender a fazer e ser na docência.

Libâneo (2012), ao discutir a questão da didática em sua abrangência no campo do conhecimento curricular, explica que a ciência pedagógica é percebida como um palco de 
PRÁTICA PROFISSIONAL DOCENTE E SENTIDOS E SIGNIFICADOS SOBRE EDUCAÇÃO E FORMAÇÃO

tópicos sobre os dados educativos, com especificidades próprias que, nas análises dos fenômenos da educação, dialoga com outras ciências tais como a sociologia, psicologia, antropologia, história, que também concebem a educação como um de seus pontos de exame.

Considerando a importância da didática, Pimenta e Anastasiou (2002) expõem que o movimento nas pesquisas acerca do ensino oferece inúmeras possibilidades à docência universitária e que existe uma importante contribuição desse campo didático, pois esses docentes, em seus processos formativos, podem obter respostas sobre os múltiplos fatores de experiências que conflitam e se efetivam em práticas de sala de aula, podendo ser percebidas com mais concretude e, também, possam se situar no tempo e espaço próprios de sua atuação, desenvolvendo, assim, uma ação profissional que contemple a excelência impulsionada pela reflexão contínua.

Dominar o conhecimento didático possibilita que esse docente universitário possa vislumbrar e se ajustar ao que é próprio da atividade de ensino, objeto de sua atuação, assim como aos saberes pertencentes à sua categoria profissional, pois, em meio às atividades de ensino, o docente tem como meta a viabilização de recursos para a promoção das competências intelectuais de seu alunado, sendo desenvolvidas a partir dos conhecimentos sistematizados nos conteúdos curriculares da universidade.

Compreendemos, também que, uma vez que o ensino e a aprendizagem possuem influência decisiva no desenvolvimento dos indivíduos - no caso da pesquisa desenvolvida tratam-se de estudantes do ensino superior de cursos da área de Ciências Sociais Aplicadas - a apreensão da conceituação de educação é imprescindível para o exercício docente, principalmente se considerarmos os objetivos estabelecidos nas instituições privadas brasileiras.

Na pesquisa desenvolvida buscamos a especificidade da educação que fundamente uma ação educativa libertadora, pois uma vez compreendendo a sua natureza podemos ver o modo que se dá essa mediação educativo-emancipadora.

Assim sendo, a educação, de uma forma geral, denota cuidado e condução para suprir exigências determinadas pelo meio social em que os indivíduos estão inseridos. Mas quando envolvemos a visão de mundo que todos os grupos sociais possuem, encontramos na questão da educação visões que podem ser convergentes e divergentes, conservadoras ou não, mesmo que partamos do pressuposto de que a educação deve ser comum para todos. No entanto, consideramos na pesquisa a concepção histórico-social, ou crítica, que entende a educação 
SOUZA, R. J.; SILVESTRE, M. A.

em um processo de superação da visão individual e liberal da ação educativa, que compromete a autonomia da ideia de constituição do homem. Podemos então dizer que, a educação está para a promoção, ou autoconstrução do ser humano.

Deste modo, a essência, ou natureza dessa concepção de educação está na autoconstrução do ser humano, é o transformar o homem em homem social. O que implica considerar que esse mesmo ser humano é constituído de subjetividades e objetividades, em que a ação educativa sobre a sua consciência deve estar na importância da constituição de uma consciência transformadora da realidade frente aos antagonismos históricos e sociais.

Isso implica um processo emancipador em que o ser humano vai desenvolvendo a capacidade de objetivar e entender o mundo, do qual faz parte, em sua relação com ele, numa dinâmica transformacional. Portanto, contra a alienação desumanizante está a luta contra a falsa consciência do mundo. Uma educação emancipadora luta para esse ser-humano-sujeito não permanecer mais acomodado e ajustado pelas determinações históricas e sociais, pois está exatamente sob a égide da liberdade.

Assim, em se tratando do contexto de trabalho dos docentes do ensino superior privado, defendemos ser imprescindível a concepção de uma educação emancipadora na formação e prática profissional dos docentes, pois segundo Boaventura de Souza Santos (2004), as universidades, bem como as IES privadas estão precisando, urgentemente, de uma reforma democrática e emancipatória.

No entanto, notamos a atribuição dada à educação nas instituições de ensino superior privadas, como sendo uma ação estratégica e responsável quase que exclusivamente por adaptar o sujeito discente ao capital, e promover a sua qualificação necessária para que este profissional seja competitivo no mercado nacional.

Nessa linha, Xidieh (2003), ao pesquisar sobre a administração, ou gestão dessas instituições do setor privado, relata que o surgimento dessas instituições se deu, em quase sua totalidade, por pessoas ou grupos de investidores desejosos de aproveitar a oportunidade que o mercado lhes oferecia. A abertura para esse investimento, tendo iniciado nos anos 80, chegando a seu ápice ao longo dos anos 90, demonstra o modus operandi predominante em tais instituições, sob o ponto de vista do retorno financeiro investido, destacando, desta forma, que "há influência ideológica, político-econômica e de poder na transposição da teoria administrativa no processo de administração das instituições de ensino do setor privado" (p. 48). 
PRÁTICA PROFISSIONAL DOCENTE E SENTIDOS E SIGNIFICADOS SOBRE EDUCAÇÃO E FORMAÇÃO

Tendo por base essa conjuntura foi necessário pensar em como o trabalho do professor do ensino superior tem sido afetado em sua tarefa de ensino e aprendizagem e qual seria o papel a ser desempenhado por ele. Nessa direção é que lançamos mão de problematizações sobre formação docente e promoção de uma educação emancipatória, orientadoras da pesquisa em questão.

\section{SENTIDOS E SIGNIFICADOS NA PSICOLOGIA HISTÓRICO-CULTURAL}

O aporte teórico da pesquisa, apresentado nesse artigo, está baseado no sistema teórico de Vygotsky (2004) em sua Psicologia Histórico-Cultural, especificamente no conceito de consciência, pois conforme explicita Castro e Alves (2012, p. 3), Vygotsky se apropria do materialismo histórico e do materialismo dialético, porque o ser humano é um indivíduo social, real e concreto, cuja singularidade se constitui enquanto membro de um grupo social, histórico e cultural específico. O desenvolvimento do psiquismo humano, desde o ponto de vista da perspectiva Histórico-Cultural, realiza-se no processo de apropriação da cultura, mediante a comunicação entre pessoas.

Analisando esse desenvolvimento, Vygotsky encontra na palavra/fala claramente um aparelho de reflexos de relação social, assinalando, também, que esse aparelho, sendo constituidor da consciência, serve para influenciar outros sistemas que constituem o homem social em sua integralidade, ou, segundo Iarochevski e Gurguenidze (2004, p. 479), essa consciência mediada pela linguagem é para Vygotsky um contato social consigo mesmo, ou entre os homens.

Desse modo, para Vygotsky (2004, p. 25), o psiquismo, ou consciência, não existe fora do comportamento, e este último não existe sem a consciência. A consciência, dessa forma, não pode ser desassociada do mundo, pois o mundo está na categoria dos excitantes e, por sua vez, a consciência no campo dos reflexos torna-se, assim, um "reflexo dos reflexos".

E nessa relação é destacado mais uma vez que o signo primordial que faz essa mediação é linguagem/palavra, mas agora por meio de um novo elemento que é o processo de interiorização $^{6}$, que se dá no movimento das categorias inter e intrapsíquicas ${ }^{7}$.

\footnotetext{
${ }^{6}$ Em seu artigo - A formação social da mente, Vygotsky, ou os tradutores utilizam "internalização", ao invés de interiorização.

${ }^{7}$ Também vista como inter e intrapsicológica.
} 
SOUZA, R. J.; SILVESTRE, M. A.

Esse processo de internalização, que é a formação da consciência do indivíduo, é, para Vygotsky, ao tratar sobre os sistemas psicológicos, a explicação e interpretação das funções psicológicas superiores dentro de uma forma que ele intitula de sistemas psicológicos, sendo que, por meio dele, é apresentado o movimento dessa internalização a partir de "complexas relações que surgem entre as funções concretas que se dão no processo de desenvolvimento e as que se desintegram, ou experimentam mudanças patológicas durante o processo de alteração" (VYGOTSKY, 2004, p. 105).

Nesse processo de internalização está a origem social da consciência. No plano psicológico, os indivíduos não têm diferença uns com os outros pela possibilidade de um desses possuir mais atenção para determinados fatos. A diferença vai estar especificamente na prática da vida social desses indivíduos, em suas relações e vinculações que se realizam a todo o momento e entre diversos pontos.

Portanto, essa consciência, para Leontiev (1978), depende da disposição de vida do indivíduo, da sua existência, ou seja, ela se constitui das relações vitais desse mesmo indivíduo em suas múltiplas condições sociais e históricas, em que a sua estruturação característica produz dadas relações conforme a atividade realizada.

Desta forma, na estrutura que forma a consciência, a significação é um componente essencial, bem como o conceito de sentido. Significação é entendida por Leontiev (1978) como a generalização da realidade que é absorvida pela palavra e cristalizada por meio das experiências e das práticas sociais dos indivíduos. Tal significação mostra também que esse indivíduo possui uma consciência individual, pois, dentro de um tempo determinado da história e envolto em leis sociais específicas, essa consciência não subtrai sua substância objetiva e não perde e nem se transforma em algo somente psicológico.

Essa significação é, para a consciência, a entrada nessa mesma realidade de reflexos do mundo sob forma de conceitos, de saberes e ações para o comportamento do indivíduo.

Considerando agora outro conceito, o do sentido, o autor esclarece que, mesmo com uma diversidade de explicações dadas para o que é o sentido, feitas por seus contemporâneos, sempre ilustravam o sentido a partir da consciência subjetiva, mas essa consciência, como vimos por meio de Vygotsky e de seus colaboradores, não pode ser entendida a partir dela mesma, mas das interações existentes no mundo o qual já mencionamos. Assim, esse sentido é, para Leontiev (1978, p.97), "antes de mais nada uma relação que se cria na vida, na atividade do sujeito". 
PRÁTICA PROFISSIONAL DOCENTE E SENTIDOS E SIGNIFICADOS SOBRE EDUCAÇÃO E FORMAÇÃO

Adentrando mais especificamente nessa relação para a nossa compreensão, enxergamos na explicação de Leontiev que essa relação, especificamente surgindo da atividade do indivíduo, se encontra e é entendida como pertencendo a este mesmo indivíduo, é sua, pois aceita a consciência disso por meio do sentido consciente que foi desenvolvido pelo arrolamento objetivo refletido na sua 'mente', em meio à aquilo que o estimula a agir e aquilo para o qual o seu ato se norteia como decorrência imediata. Na explanação de Leontiev (1978, p. 98) "é o sentido que se exprime nas significações (como o motivo nos fins) e não a significação no sentido".

No entendimento de Vygotsky (2002), o sentido tem o predomínio sobre o significado da palavra, pois este último é apenas uma das zonas do sentido.

O sentido é, desse modo, a soma de todos os acontecimentos psicológicos que a palavra abre em nossa consciência. Ele é composto por um conglomerado intricado, fluído e ativo, detentor de múltiplas zonas de equilíbrio desiguais, enquanto que o significado é mais constante e resumido. Para entendermos essa distinção, Vygotsky (2002, p. 125) expõe que "uma palavra adquire o seu sentido no contexto em que surge; em contextos diferentes, altera o seu sentido. O significado permanece estável ao longo de todas as alterações do sentido".

Com isso, a diferença entre significado e sentido está justamente no contexto das palavras. Uma determinada palavra pode ter um significado bem definido e constante, mas dependendo do contexto onde foi formulada e anunciada, adquire um sentido que pode ser muito mais amplo do seu significado.

Em termos concretos, a conscientização dos docentes do ensino superior começa pela busca de uma posição de enfrentamento da realidade da educação desenvolvida nas instituições de ensino. Isto significa que os muitos docentes no Brasil, sejam estes na IES privadas, ou públicas — que são semelhantes em muitos aspectos — podem descobrir numa concepção de educação emancipadora um substancial auxílio ou, talvez, até mesmo um ponto de partida para uma nova prática.

\section{PROCEDIMENTOS METODOLÓGICOS}

Para a investigação acerca de quais os sentidos e significados de educação e formação conduzem a prática profissional do docente do ensino superior privado, foi eleita a abordagem qualitativa na tentativa de compreensão dessa questão extremamente particular a 
SOUZA, R. J.; SILVESTRE, M. A.

partir do referencial de Vygotsky, em sua Psicologia Histórico-Cultural, especificamente no conceito de consciência, juntamente com uma concepção de educação emancipatória.

Para a coleta de informação, optamos pela técnica do Grupo Focal (Focus Group - GF), técnica de coleta de dados que toma como unidade de análise o próprio grupo, onde o que é analisado não é a posição particular apresentada por um de seus participantes, mas essa posição, mesmo que não sendo partilhada por todos os outros integrantes, é tomada como pertencente ao grupo inteiro, no processo de exame dos resultados obtidos. Com isso, a utilização do GF responde a abordagem qualitativa, auxiliando a discussão de algumas questões, como instrumento qualificado junto a um conjunto de atores sociais que inicialmente definimos como professores que atuam diretamente no ensino superior privado.

Segundo Gatti (2005), a ênfase recai sobre a interação dentro do grupo, por que há interesse não somente no que as pessoas pensam e expressam, mas também em como elas pensam e porque pensam o que pensam. Assim, a autora, explica que essa técnica tem por objetivo

[...] compreender processos de construção da realidade por determinados grupos sociais, compreender práticas cotidianas, ações e reações a fatos e eventos, comportamentos e atitudes, constituindo-se uma técnica importante para o conhecimento das representações, percepções, crenças, hábitos, valores, restrições, preconceitos, linguagens e simbologias prevalentes no trato de uma dada questão por pessoas que partilham alguns traços em comum (GATTI, 2005, p. 11)

Por isso, no problema levantado em nossa pesquisa, o trabalho do GF impulsionou, com grandes possibilidades, obter as concepções sobre educação e formação dos docentes das IES privadas.

Assim, estruturamos o percurso empírico desenvolvendo um roteiro com dez questões semi-estruturadas relacionadas com a nossa investigação, que nos orientou para a estimulação da discussão com dois grupos de professores de duas IES privadas localizadas na Cidade de São Paulo. Em cada uma delas desenvolvemos o GF com cinco e quatro docentes, respectivamente, contando, portanto com a participação de 9 professores.

Para a composição desses grupos, se levou em consideração: 1) a homogeneidade, destacando que todos os docentes envolvidos atuassem na área das ciências sociais aplicadas (Economia, Finanças, Comercio Exterior, Administração de Empresas, Direito, Recursos Humanos etc.) e 2) experiência profissional de atuação no ensino superior privado (graduação) de, no mínimo, cinco anos lecionando. 
PRÁTICA PROFISSIONAL DOCENTE E SENTIDOS E SIGNIFICADOS SOBRE EDUCAÇÃO E FORMAÇÃO

Tendo por base as informações coletadas por meio do GF, contidas nas narrativas dos dois grupos de professores, recorremos ao procedimento de análise do material denominado por Aguiar e Ozella (2006 e 2013) de Núcleos de Significação. A organização teóricometodológica de sua proposta tem base considerável em Vygotsky, bem como no método materialista histórico e dialético, para atuação nas categorias de linguagem, pensamento, significado e sentido, assim também como as necessidades e motivos.

Assim, os autores possuem a dialética como método, ou recurso metodológico de “crítica radical das visões reducionistas, objetivistas e subjetivistas, a discussão sobre a relação aparência - essência, parte - todo, a importância da noção de historicidade, de processo e a noção de mediação" (AGUIAR; OZELLA, 2006, p. 224).

A análise e tratamento dos dados, nesse sentido, ultrapassou o aparente, da simples interpretação da apresentação de alguns dados do fenômeno, para uma análise mais acurada dos processos históricos e sociais que corroboraram para o fato. Para análise dos dados partimos, portanto, da ideia de que os docentes são estabelecidos na e com a sua atividade social-profissional, pois ao lançar sua forma de atuação no mundo, na sociedade, nos revelam na amplitude de suas expressões "a historicidade social, a ideologia, as relações sociais, o modo de produção. Ao mesmo tempo, esse mesmo homem expressa a sua singularidade, o novo que é capaz de produzir, os significados sociais e os sentidos subjetivos". (AGUIAR; OZELLA, 2006, p. 224).

A relação de mediação nesse processo dialético do ser humano possui um instrumento importante que é a linguagem na constituição desse homem social, pois no processo de internalização desse social, essa ferramenta não simplesmente o transpõe, mas como força psicológica possibilita também o seu significado. Portanto, foi por meio e pela mediação da linguagem que conseguimos obter os sentidos e significados desses sujeitos concretos.

Com base nesse referencial teórico metodológico o procedimento de análise se deu em três níveis: a) leitura flutuante e organização do material na disposição de pré-indicadores; b) formação dos indicadores e conteúdos temáticos decorrentes do primeiro nível; c) construção dos núcleos de significação d) análise dos núcleos.

O trabalho de explicitar os núcleos de significação na fala dos sujeitos requereu, após os primeiros passos empíricos, um trabalho árduo de interpretação para alcançar os aspectos fundantes de suas falas, para então, obter suas zonas de sentidos. 
SOUZA, R. J.; SILVESTRE, M. A.

O agrupamento realizado como fruto dessa nossa interpretação, evidencia uma realidade sócio-histórica atravessada por determinações e embricamentos que, só podem ser explicitados não por uma interpretação reducionista a partir de uma relação teórico-prática, mas, sim, por meio da relação dialética com essa realidade.

Diante disso, limitados pelo objetivo desse artigo, apresentaremos somente o resultado parcial desse processo. No Quadro 1 identificamos os indicadores desvelados a partir da lista de pré-indicadores encontrados nas narrativas dos sujeitos e os dois Núcleos de Significação.

\begin{tabular}{|c|c|}
\hline Indicadores & Núcleos de significação \\
\hline $\begin{array}{l}\text { 1) A generalização da educação como mercadoria e } \\
\text { a negação do seu caráter real. } \\
\text { 2) A flexibilidade, racionalidade, produtividade e } \\
\text { competitividade, descaracterizando o sentido sócio- } \\
\text { político da educação } \\
\text { 3) A educação no limiar entre o bem público e o } \\
\text { acúmulo de capital } \\
\text { 4) Concepção fragmentária, incoerente, } \\
\text { desarticulada e degradada da educação }\end{array}$ & $\begin{array}{c}\text { A educação como lugar definitivamente central } \\
\text { no processo de produção e reprodução do } \\
\text { mercado. }\end{array}$ \\
\hline $\begin{array}{l}\text { 5) Experiência e desejo como habilitação à docência } \\
\text { 6) Experiência e técnicas profissionais apuradas, } \\
\text { nem por isso, docentes mais competentes. } \\
\text { 7) Ausência do significado da formação do docente } \\
\text { enquanto educador dotado de fundamentação teórica } \\
\text { consistente } \\
\text { 8) Redução do ferramental didático-pedagógico para } \\
\text { soluções simplistas. } \\
\text { 9) Ausência de abordagem pedagógica e referência } \\
\text { explícita à educação no seu processo formativo }\end{array}$ & $\begin{array}{l}\text { A formação do docente da IES por meio de } \\
\text { valores de outra natureza. }\end{array}$ \\
\hline
\end{tabular}

Quadro 1. Organização dos indicadores e Núcleos de Significação (elaborado pelos autores)

Nesse artigo apresentamos, sumariamente, somente o resultado da análise do segundo Núcleo de Significação, na perspectiva de problematizar a importância da formação pedagógica de professores das instituições de ensino superior.

\section{OS SENTIDOS E SIGNIFICADOS APREENDIDOS}

O segundo Núcleo de Significação A formação do docente da IES por meio de valores de outra natureza alude, sobretudo, à complexa formação dos docentes das IES privadas, que ao invés de significarem sua ação baseada na natureza pedagógica, tem não somente a educação, mas agora também o processo formativo, pela égide da lógica do produto, do mercado. 
PRÁTICA PROFISSIONAL DOCENTE E SENTIDOS E SIGNIFICADOS SOBRE EDUCAÇÃO E FORMAÇÃO

A opção ideológica do mercado, aparece na fala dos docentes como ação inteiramente saturada desse sentido para o seu processo de constituição como docentes universitários, o que nos levou a entender e estabelecer esse núcleo de significação, explicitando sua maneira de pensar, sentir e agir frente a um tipo do que nos é apresentado como sua formação.

Ao afirmarem que aprenderam pelo exemplo de outros colegas formadores, os docentes realçam que a ciência pedagógica não contribuiu muito para isso. Adotam que, a pedagogia e a mediação de conhecimentos historicamente constituídos acerca da educação, por si sós, não são satisfatórias para garantir a formação para o processo de ensino e aprendizagem:

Eu acho que aprendi fazendo, em marcha (...)Pelo menos na nossa área aqui, que é a área de direito e a área de negócios. Não há essa (...) Quer dizer, a gente vai para sala de aula e já aprendeu. Com nossos mestres lá, como é que eles trabalhavam, procura copiá-los um pouco até criar uma forma particular da gente trabalhar.

Essa fala indica como os docentes são atravessados diretamente pela lógica de suas profissões anteriores à docência, e, de modo especial, pelo exemplo que eles podem apreender dos docentes que os formaram, destacando a ideia de que "quem sabe fazer sabe ensinar". $\mathrm{O}$ sentido aprendido quanto a formação para esse tipo de docência está, deste modo, primeiramente na sua experiência como profissional autônomo que, intuindo, ou improvisando sobre outra rotina, agora, a de professor, inicia a sua constituição como docentes em uma IES.

Em seu discurso, podemos explicitar que o pedagógico e o didático estão associados ao teórico, e reforçam a sua opção e o sentido da formação ancorados na dimensão técnica para o processo de ensino e aprendizagem:

Embora este aprendizado se dê muito na prática do dia a dia, mas, sempre foi consenso nosso de que se nós pudéssemos ter a oportunidade de ter uma ferramenta, que pudesse ajudar seria bem-vindo. Só que é muito importante não só na parte da graduação, mas neste curso que a gente observa de prática docente não seria possível ainda identificar algo prático que pudesse realmente dar instrumental de aula que atendesse essa nossa área de negócio.

E complementam: "aquelas aulas de didática de ensino superior (...) é como dar uma aula. Muita teoria, tudo teórico (...)Você estuda os teóricos, lê os livros de Vygotsky, sei lá o que(...) Mandam você comprar uma série de livros".

Revista Reflexão e Ação, Santa Cruz do Sul, v. 24, n. 3, p.141-161, Set./Dez. 2016.

http://online.unisc.br/seer/index.php/reflex/index 
SOUZA, R. J.; SILVESTRE, M. A.

Para Cunha (2006), o desprestígio do conhecimento pedagógico, ou "teórico" como eles nos sinalizam, indica os seus valores e sentidos "pedagógicos", regulados, assim, por outra lógica, o qual ela chama de processo de padronização por meio de uma única forma de conhecimento para a formação docente. Assim, para a autora, "o dilema consiste em que a validação de uma só forma de conhecimento provoca a cegueira epistemológica e valorativa, destruindo as relações entre os objetos e, nessa trajetória, eliminando as demais formas de conhecimento" (p. 14).

Os docentes afirmam que, esse conhecimento teórico, deve servir para lhes apresentar o como dar aula, demonstrando assim, essa ausência epistemológica - "O que nós precisamos é de uma metodologia efetiva, mas você sobe num tablado e diz: "Pô tudo aquilo que eu li, como é que eu uso aqui" - e, também, como consequência disso, a redução do processo de ensino e aprendizagem ao aspecto puramente técnico. Essa necessidade de uma ferramenta efetivamente técnica e operacional vai significando a formação com uma identidade relativa a posição de profissionais do mercado corporativo.

Essa concepção do "fazer pedagógico" no foco de técnicas pragmáticas, está bem no nível de discurso do mercado que, a partir da ideia de eficiência/ineficiência, assume a regulação dos processos educativos, para ditar o que é o padrão da qualidade educativa.

Por outro lado, os docentes não negam totalmente a importância do saber fazer pedagógico, mas o coloca em uma subcategoria, desqualificando essa prática educacional na utilização tão somente de acordo com uma necessidade que, não se demonstra claramente como planejamento adequado de uma técnica para aplicação educativa - "Esses pequenos cursos como o Prof. " $X$ ” lembrou, esses (...) teóricos, que foram dados aqui pela instituição, também dá um empurrãozinho, mas efetivamente que você fala "Puxa, me ensinaram como dar aula hoje."

Diante disso, enxergamos nos docentes uma preocupação na relação entre teoria e prática, que atravessa boa parte de suas falas, é um ponto muito evidente acerca do seu processo de formação.

O que os docentes apresentam é o seu ideário "pedagógico" atravessado por valores dominantes que, aparentemente destoam do pedagógico em sua valorização e sentido na humanização. Com isso, no discurso dos docentes o sentido de formação por meio do pedagógico está compreendido como desnecessária, principalmente se a dimensão humana do processo de ensino e aprendizagem for o foco - " "[...] se propõe muito com a questão do relacionamento professor-aluno. Então, fica muito no campo da teoria." O emprego de Revista Reflexão e Ação, Santa Cruz do Sul, v. 24, n. 3, p.141-161, Set./Dez. 2016.

http://online.unisc.br/seer/index.php/reflex/index 
PRÁTICA PROFISSIONAL DOCENTE E SENTIDOS E SIGNIFICADOS SOBRE EDUCAÇÃO E FORMAÇÃO

palavras, ou frases como "tornar a aula interessante", "mas, não adianta" é uma demonstração simbólica, que além de mostrar o seu ideário, significa o que é a formação pela teoria pedagógica, dando lugar a outro sentido para formação:

Eu venho de empresa, e trabalhei 30 e tantos anos em empresa, pra quem precisa trabalhar com grupo para atender clientes... Se fazem treinamentos muito específicos, sobre como se portar diante dos clientes, microfilmagens com simulações, filmagens onde depois você tem um especialista que te dá as informações "Olha você tem que por a mão na boca, não faça isso, não fica segurando a caneta, enfim, dicas efetivas de como se portar, coisa que você falou bem por mais que você vá em aulas de técnicas de ensino, didática do ensino e tal, é teórico, pede a prática[...]

Até aqui podemos identificar que os docentes vivem uma contradição muito forte entre as experiências da antiga profissão e a docência, privilegiando, sobremaneira, a necessidade de aprender o como fazer em detrimento da discussão sobre o para que fazer, desconsiderando, assim, os objetivos da educação como norteadores das práticas.

Assim, a partir do nosso referencial que nos possibilita analisar concretamente essa subjetividade, ou ponderar sobre a contradição pela sua constituição histórica, na fala desses docentes temos o dado-sempre-já-dado para essa análise. As condições existentes da unidade entre teoria e prática mostram essa contradição, que eles têm, a partir dela mesma, pois em um momento afirmam a sua necessidade de ajuda pela pedagogia e didática - "O que nós precisamos é de uma metodologia efetiva" -, em outro momento nega a sua ciência - "mas você sobe num tablado e diz: "Pô tudo aquilo que eu li, como é que eu uso aqui". Nesse sentido, essa negação é melhor ilustrada com a seguinte fala:

Agora, técnicas da aula, como você utilizar transparência, como se portar na sala de aula (...) como dividir a lousa, aproveitar melhor o espaço da lousa, usar esses recursos que hoje em dia praticamente todas as escolas nos disponibilizam, de áudio visual, Power Point, essa coisa. Eu nunca vi nestes cursos.

De acordo com os docentes, paradoxalmente a noção "teórica" é caracterizada como algo diretamente voltado para a obstrução do seu ensino e aprendizagem. Ao afirmar que "Por isso, que eu digo, acho que os três aqui, a grande maioria dos professores, o senhor também, imagino que aprenderam mesmo fazendo" demonstra um tipo de mediação que advém de 
SOUZA, R. J.; SILVESTRE, M. A.

seus saberes e experiências anteriores à docência, portanto, mediação da prática do campo científico de onde são oriundos.

Por fim, vale reiterar que a importância deste núcleo de significação nos leva à compreensão do processo formativo dos docentes na medida em que, ao apreendermos os sentidos e significados que eles atribuem a sua constituição como docentes, podemos clarificar ainda as questões que eles mesmos vão se colocando sobre sua atividade nas IES, bem como suas compreensões acerca do ensino e aprendizagem.

\section{CONCLUSÃO}

Diante do exposto nesse artigo, procuramos apresentar como resumo da pesquisa realizada, uma contribuição teórico-investigativa, trazendo para o campo da formação de professores, a preocupação com o que é nos revelado sobre a consciência dos docentes de IES privadas, na construção de sua concepção de formação, à prática educacional nessas instituições.

A análise das narrativas dos docentes investigados só foi possível a partir do momento que conhecemos um pouco mais a sua origem como profissionais de diversos outros campos que não o da educação. Para Vygotsky (2003), isso é possível não por lampejos luminosos de uma análise introspectiva, mas entendendo "as ligações reais entre os estímulos externos e as respostas internas que são à base das formas superiores de comportamento" (p. 84). Para isso, a psicologia histórico cultural e a escola de Vygotsky foram de extrema importância.

Com essa aproximação identificamos que os sentidos e significados de formação desses docentes, estão postos mais na base de suas profissões anterior à docência, do que em aportes desenvolvidos por meio de um tipo de formação inicial ou continuada no âmbito pedagógico, atividades praticamente ausentes em instituições de ensino superior.

Afirmar isso, não caracteriza a nossa conclusão como enviesada. Muito pelo contrário, da nossa análise o contexto das falas nos proporcionou interpretá-las como uma generalização da própria lógica do mercado e, tendo por base esta constatação, defendemos a importância de processos formativos para docentes que atuam no ensino superior como forma de possibilitar uma apreensão do significado, antes de tudo, formador e educacional, do trabalho docente.

\section{PROFESSIONAL PRACTICE TEACHERS AND SENSE AND MEANING OF EDUCATION AND TRAINING}

Revista Reflexão e Ação, Santa Cruz do Sul, v. 24, n. 3, p.141-161, Set./Dez. 2016.

http://online.unisc.br/seer/index.php/reflex/index 


\begin{abstract}
This article aim is to show the results of a research in which we tried to investigate what kind of conceptions of education and training lead the professional practice of teachers from private higher education, based on the theoretical framework of Cultural-Historical Psychology in its dialogue with the educational field. This is a qualitative research approach which has as procedure theoretical and methodological Focus Group (Gatti, 2005), conducted with teachers in private higher education institutions. For the treatment of data we made use of the Core of Meanings (AGUIAR; OZELLA, 2006), which, through the narrative of the subject, helped us to identify the conceptions of education and training reflected in the discourse. As a result it was found that the meanings of education and training are more on the basis of his previous professions to teaching than in contributions developed through initial or continuing education, virtually absent processes in higher education institutions.
\end{abstract}

Keywords: Teacher Training; University Pedagogy; Higher education; Design education; Senses and Meanings

\title{
PRÁCTICA PROFESIONAL DE PROFESSSORES Y EL SENTIDO Y SIGNIFICADO DE EDUCACIÓN Y FORMACIÓN
}

\section{Resumen}

Este artículo presenta los resultados de la investigación que buscaban revelar cuales són los sentidos y significados de la educación y la formación para la práctica profesional de la enseñanza en la educación superior privada, con base en el marco teórico de la psicología histórico-cultural en su diálogo con el campo de la educación. Es un enfoque de investigación cualitativa, que adoptó como procedimiento de investigación lo Grupo Focal desarrollado con profesores de los centros privados de educación superior. Fue utilizado en el tratamiento de los datos, el procedimiento de análisis llamado Núcleos del Significación (Aguiar, Ozella, 
SOUZA, R. J.; SILVESTRE, M. A.

2006) que permitió una aproximación de los sentidos y significados refleja en los discursos de estos maestros. Como resultado se encontró que los sentidos de la educación y la formación son más puestos sobre la base de sus profesiones anteriores a la enseñanza que en las contribuciones desarrolladas a través de la educación inicial o continua, prácticamente ausentes en los procesos de las instituciones de educación superior.

Palabras clave: Formación del Profesorado; Pedagogía Universitaria; Enseñanza Superior; Concepción de la Educación; Sentidos y Significados

\section{REFERÊNCIAS}

AGUIAR, M. J.; OZELLA, S. Núcleos de significação como instrumento para a apreensão da constituição dos sentidos. Psicologia: Ciência e Profissão, Brasília: Conselho Federal de Psicologia, v. 26, n. 2, p. 222-246, 2006.

. Apreensão dos sentidos: aprimorando a proposta dos núcleos de significação. Revista Brasileira de Estudos Pedagógicos, Brasília: Inep, v. 94, n. 236, p. 299-322, jan./abr. 2013.

CASTRO, R. F. e ALVES, C. V. P. Consciência em Vygotsky: aproximações teóricas Disponível em:

<http://www.ucs.br/etc/conferencias/index.php/anpedsul/9anpedsul/paper/viewFile/744/375>. Acesso em: 20 set. de 2012.

CUNHA, M. I. (org.). Pedagogia universitária: energias emancipatórias em tempos neoliberais. Araraquara, SP: Junqueira\&Marin, 2006.

FREIRE, P. Educação como prática da liberdade. Rio de Janeiro: Paz e Terra, 1967.

GATTI, B. A. Grupo Focal na pesquisa em Ciências Sociais e Humanas - Brasília: Líber Livro Editora, 2005.

INEP. Censo da educação superior 2010 - resumo técnico. Disponível em:

<http://portal.inep.gov.br/web/censo-da-educacao-superior/resumos-tecnicos >. Acesso em: 04 out. de 2012 - pp. 30-33.

. Sinopses Estatísticas da educação superior 2010. Disponível em <http://portal.inep.gov.br/c/journal/view_article_content?groupId=10157\&articleId=84499\&v ersion=1.3 $>$. Acesso em: 04 out. de 2012. 
PRÁTICA PROFISSIONAL DOCENTE E SENTIDOS E SIGNIFICADOS SOBRE EDUCAÇÃO E FORMAÇÃO

. Censo da educação superior 2011 - resumo técnico. Disponível em:

<http://portal.inep.gov.br/web/censo-da-educacao-superior/resumos-tecnicos $>$. Acesso em: 24 nov. de 2013 - pp. 110-116.

IAROCHEVSKI E GURGUENIDZE IN VYGOTSKY, L. S. 1896-1934. Teoria e método em Psicologia. 3. ed. São Paulo: Martins Fontes, 2004.

LEONTIEV, A. N. O desenvolvimento do psiquismo. Lisboa: Livros Horizontes, 1978.

LIBÂNEO, J. C. Ensinar a aprender e aprender a ensinar: o lugar da teoria e da prática em didática IN: LIBÂNEO, C. L. e ALVES, N. (Ogs.). Temas de Pedagogia: diálogos entre didática e currículo. São Paulo: Cortez, 2012.

MASETTO, M. T. Competências pedagógicas do professor universitário. São Paulo: Summus, 2003.

PIMENTA, S. G. e ANASTASIOU, L. G. C. Docência no ensino superior. São Paulo: Cortez, 2002.

VEIGA, I. P. A. Alternativas pedagógicas para a formação do professor da Educação Superior. IN: VEIGA, I. P. A. \& VIANA, C. M. Q. Q. (Orgs.). Docentes para a educação superior: processos formativos. Campinas, SP: Papirus, 2010.

VYGOTSKY, L. S. 1896-1934. Teoria e método em Psicologia. 3. ed. São Paulo: Martins Fontes, 2004.

Pensamento e linguagem. São Paulo: Martins Fontes, 2002.

XIDIEH, D. B. A teoria administrativa e a administração das instituições de ensino superior do setor privado. 2003. 72 f. Dissertação (Mestrado em Educação) - Universidade Estadual de Campinas (UNICAMP), Campinas, São Paulo, 2003. Disponível em <http://www.bibliotecadigital.unicamp.br/document/?code $=$ vtls000298601\&fd=y >. Acesso em: 07 jul. de 2012.

Data de recebimento: 22/05/2016

Data de aceite: 20/10/2016 